\title{
CRESCIMENTO E EXTRAÇÃO DE MICRONUTRIENTES EM ABACAXIZEIRO 'VITÓRIA'?
}

\author{
HERNANDES DE OLIVEIRA FEITOSA², AIALA VIEIRA AMORIM ${ }^{3}$, \\ CLAUDIVAN FEITOSA DE LACERDA ${ }^{4}$, FLÁVIO BATISTA DA SILVA 5
}

RESUMO - No presente estudo, foram avaliadas a produção de massa seca e a extração de micronutrientes do abacaxizeiro 'Vitória', adubado com micronutrientes aplicados via solo e por adubação foliar. O experimento foi instalado em abril de 2009, em uma área de 0,178 ha localizada no Perímetro Irrigado Baixo Acaraú, na região norte do Estado do Ceará. O delineamento estatístico empregado foi o de blocos casualizados, no arranjo de parcelas subsubdivididas, com quatro doses de FTE-12 (parcelas), quatro níveis de adubação foliar (subparcelas), quatro avaliações trimestrais (subsubparcelas) e cinco repetições. Foram feitas avaliações de produção da massa seca da parte aérea e de extração de micronutrientes. A produção da massa seca e a extração de Fe, Zn, Mn e B foram influenciadas pela idade fisiológica e pelas doses de micronutrientes aplicadas tanto no solo como nas folhas. As maiores doses de micronutrientes resultaram em maior crescimento da planta, o que levou a maiores extrações de micronutrientes, porém não chegando ao ponto de máximo, indicando que a cultura pode responder a doses maiores de micronutrientes.

Termos para indexação: Ananas comosus, micronutrientes, adubação.

\section{GROWTHAND MICRONUTRIENTS EXTRACTION BY 'VITORIA' PINEAPPLE}

\begin{abstract}
The study aimed to evaluate the dry mass production and the extraction of micronutrients by the 'Vitória' pineapple, grown under increasing doses of micronutrients applied in the soil and through leaf fertilization. The test trial was installed in April 2009, in an area of 0.178 ha located in the Baixo Acaraú irrigated perimeter, in the northern region of Ceará state. The statistical design was a randomized block arrangement in a split plot design with four levels of FTE-12 (plots), four levels of leaf fertilization (subplots), four quarterly evaluations (subsubplots) and five replications. The production of shoot dry mass and the extraction of micronutrients were assessed. The dry mass production and the extraction of $\mathrm{Fe}, \mathrm{Zn}, \mathrm{Mn}$ and $\mathrm{B}$ were influenced by the physiological age and by the doses of micronutrients applied, either directly to the soil or on the leaves. Higher doses of micronutrients were more expressive allowing higher plant growth, resulting in higher extraction of micronutrients, however, not reaching a maximum point, indicating that the crop can respond to higher doses of nutrients.
\end{abstract}

Index terms: Ananas comosus, micronutrients, fertilization.

\section{INTRODUÇÃO}

O Brasil é um dos três maiores produtores de frutas tropicais do mundo. Sua produção superou 43 milhões de toneladas em 2008, o que representa 5\% da produção mundial, ficando atrás apenas da China e da Índia (FAO, 2010). Dentre as principais fruteiras tropicais, o abacaxi (Ananas comosus) ocupa lugar de destaque no cenário mundial. Os principais produtores mundiais dessa frutífera, em 2009, foram:
Filipinas, Tailândia, Costa Rica, Indonésia e Brasil (FAO, 2010). Segundo dados do Agrianual (2011), a região Nordeste do Brasil é a maior produtora, contribuindo com $37,34 \%$ da produção nacional, numa área plantada de 22.687 ha.

A cultura do abacaxizeiro sempre se destacou na fruticultura nordestina, graças não só às qualidades do fruto, que é bastante apreciado em todo o mundo, mas, principalmente, pela sua alta expressão econômica dentro do setor frutícola. Esta cultura gera

\footnotetext{
${ }^{1}$ Trabalho Sinfruit 160 - Simpósio Internacional de Fruticultura - Avanços na Fruticultura (17 a 21 Outubro)

${ }^{2}$ Engo. Agrônomo, doutorando do curso de Engenharia Agrícola, DENA-UFC; Av. Mister Hull, s/n, Câmpus do Pici, bloco 804, CEP: 60455-760, Fortaleza-CE. E-mail: hernandes.oliveira@gmail.com

${ }^{3}$ Dra. em Agronomia/Fitotecnia, Departamento de Fitotecnia-UFC, Fortaleza-CE. E-mail:aialaamorim@hotmail.com

${ }^{4}$ Dr. Professor do Departamento de Irrigação e Drenagem, DENA-UFC, Fortaleza-CE. E-mail:cfeitosa@ufc.br

${ }^{5}$ Engo. Agrônomo, Mestrando do curso de Desenvolvimento Regional Sustentável, PRODER-UFC, Fortaleza-CE.

E-mail:agroflaviobatista@yahoo.com.br
} 
centenas de empregos diretos e indiretos durante todo o ciclo, isto porque a exploração agrícola dessa frutífera não pode ser mecanizada, necessitando-se da mão de obra humana para o seu cultivo (BRITO NETO et al., 2008). O acompanhamento do crescimento dessa planta é de extrema importância, visto que plantas vigorosas, de grande porte e com nutrição adequada, poderão produzir frutos de melhor qualidade.

Um dos principais fatores determinantes de melhorias no crescimento das plantas é a nutrição. Em geral, pouco se conhece sobre o efeito da adubação com micronutrientes nas culturas tropicais. Para Yamada (2004), o consumo de micronutrientes vem crescendo em ritmo acelerado, sendo este aumento indicado como um dos prováveis responsáveis pela melhoria no crescimento e produção de diversas culturas. Alguns trabalhos reportam a importância do boro e do zinco na cultura do abacaxizeiro (MAEDA et al., 2011; SIEBENEICHLER et al., 2008). Entretanto, segundo Siebeneichler et al. (2008), atualmente, parece estar havendo certa conscientização por parte dos agricultores quanto ao uso de micronutrientes na cultura do abacaxizeiro, mas sua utilização geralmente se faz de forma empírica.

Assim, buscou-se avaliar a produção de massa seca e a extração de micronutrientes pelo abacaxizeiro 'Vitória', em resposta a doses de micronutrientes aplicados via solo e por adubação foliar, nas condições climáticas do Perímetro Irrigado do Baixo Acaraú-CE.

\section{MATERIAL E MÉTODOS}

O experimento foi iniciado em abril de 2009, numa área de 0,178 ha, localizada no Perímetro Irrigado Baixo Acaraú, na região norte do Estado do Ceará. De acordo com a classificação de Köeppen, a área está sob influência do clima Aw' (tropical chuvoso) com coordenadas geográficas $3^{\circ} 07^{\prime} 13$ ' S, $40^{\circ} 05^{\prime} 13^{\prime} \mathrm{W}$. O solo da área experimental apresenta textura arenosa, com elevada capacidade de infiltração e baixa capacidade de retenção de água. As características químicas do solo, medidas na camada de 0 a $20 \mathrm{~cm}$, são: pH 5,8, CE $0,15 \mathrm{dS} \mathrm{m}^{-1}$, $0,05 \mathrm{~g} \mathrm{~kg}^{-1}$ de matéria orgânica e 20;15; 43 e $18 \mathrm{mg}$ $\mathrm{kg}^{-1}$ de Fe, Zn, Mn e B, respectivamente. Para essas determinações, foi utilizado o extrator Mehlich-1.

O preparo do solo constou de uma aração seguida de gradagem cruzada e uma adubação orgânica com esterco misto à base de esterco bovino mais esterco caprino, em dose equivalente a $2,0 \mathrm{~kg}$ de esterco por 1,2 $\mathrm{m}^{2}$ como fonte de $\mathrm{N}$. Os canteiros foram confeccionados pelo rottcanteirador, nas dimensões de 1,20 m de largura com 0,25 m de altura. Após o preparo dos canteiros, realizaram-se a abertura das covas e a adubação com FTE-12, de acordo com os tratamentos, e fosfato na dose de $250 \mathrm{~kg} \mathrm{ha}^{-1} \mathrm{de}_{2} \mathrm{P}_{5}$ por ocasião do plantio.

A cultivar de abacaxi utilizada foi a 'Vitória', obtida de mudas micropropagadas após aclimatadas por seis meses, sendo, em seguida, transplantadas em fileiras duplas, no espaçamento de $0,90 \times 0,40$ x 0,30 m, com área de $0,195 \mathrm{~m}^{2}$ planta $^{-1}$. Após o transplantio, foi colocada a bagana de carnaúba em quantidade equivalente a $600 \mathrm{~g} \mathrm{~m}^{-2}$. Cada parcela foi constituída de 352 plantas $\left(68,64 \mathrm{~m}^{2}\right)$ e subparcela com 88 plantas $\left(17,16 \mathrm{~m}^{2}\right)$, totalizando 7.040 plantas numa área total de 0,178 ha.

O delineamento estatístico empregado foi o de blocos casualizados, no esquema de parcelas subsubdivididas, com quatro doses de FTE-12 (parcelas), quatro níveis de adubação foliar (subparcelas), quatro avaliações trimestrais (subsubparcelas) e cinco repetições. As parcelas constaram de quatro doses de adubação convencional com FTE-12: T1 (sem adubação); T2 (60 kg ha-1); T3 (120 kg ha-1), e T4 (180 kg ha-1) aplicado no plantio. Nas subparcelas, os tratamentos foram constituídos de quatro níveis de adubação foliar com micronutrientes: T1 (sem adubação); T2 (9 adubações foliares, usando um total de 540,75 $\mathrm{g} \mathrm{ha}^{-1}$ de Fe, 394,17 $\mathrm{g} \mathrm{ha}^{-1} \mathrm{de} \mathrm{Mn}$, $182,7 \mathrm{~g} \mathrm{ha}^{-1}$ de $\mathrm{Zn}, 150,57 \mathrm{~g} \mathrm{ha}^{-1}$ de $\mathrm{Cu}$ e $100,8 \mathrm{~g}$ ha $^{-1}$ de B); T3 (9 adubações foliares, usando o dobro das quantidades do nível AF1), e T4 (9 adubações foliares, usando o triplo das quantidades do nível AF1). Os compostos utilizados para fazer a solução de micronutrientes foram: $\mathrm{FeSO}_{4} \cdot 7 \mathrm{H}_{2} \mathrm{O}, \mathrm{H}_{3} \mathrm{BO}_{3}$, $\mathrm{MnSO}_{4} \cdot 4 \mathrm{H}_{2} \mathrm{O}, \mathrm{ZnSO}_{4} \cdot 7 \mathrm{H}_{2} \mathrm{O}$ e $\mathrm{CuSO}_{4} \cdot 5 \mathrm{H}_{2} \mathrm{O}$. As adubações foliares foram realizadas mensalmente, sendo as concentrações definidas tomando-se como base a solução nutritiva de Murashige e Skoog modificada. Com o objetivo de favorecer a absorção dos micronutrientes, a partir do terceiro mês, aplicou-se ureia a $2 \%$.

A aplicação dos macronutrientes foi realizada via fertirrigação, totalizando $528 ; 537 ; 78 ; 80 ; 20$ e $24 \mathrm{~kg} \mathrm{ha}^{-1}$ de ureia, sulfato de potássio, ácido fosfórico, MAP, nitrato de cálcio e sulfato de magnésio, respectivamente. O manejo da irrigação foi realizado em base em sensores de umidade do solo TOPDEA, instalados aos 15 e $25 \mathrm{~cm}$ de profundidade do solo, objetivando repor o armazenamento de água no solo (CRUZ et al., 2010).

No primeiro mês após o transplantio, foi realizado o controle preventivo da podridão do olho do abacaxizeiro com o fungicida Aliette e, aos seis meses, as plantas sofreram ataque de cochonilha- 
-branca, que foi controlada com a aplicação de Methyl parathion $600 \mathrm{CE}$.

As plantas foram coletadas até os nove meses, numa frequência trimestral, sendo a primeira amostragem composta de trinta mudas retiradas quando as mesmas foram transplantas para o campo. Na segunda coleta, retiraram-se quatro plantas por subparcela, sendo esse número reduzido à metade na terceira $\mathrm{e}$ quarta coletas. Para avaliações da fitomassa seca da parte aérea, as plantas foram secadas em estufa de circulação forçada com a temperatura de $60^{\circ} \mathrm{C}$, por um período de quatro dias. Após a secagem das plantas, essas foram pesadas e moídas em moinho tipo Willey, e acondicionadas em sacos de papel para análises dos teores totais de Fe, Mn, Zn e B, seguindo a metodologia proposta por Malavolta et al. (1997), e o resultado dos teores foi multiplicado pela matéria seca das plantas por hectare para obter as quantidades totais extraídas.

As análises estatísticas, para as variáveis analisadas, foram realizadas pelo método de análise de variância, utilizando o valor máximo a 5\% de significância para o Teste $\mathrm{F}$ e realizando-se análises de regressão para os casos em que ocorreu efeito significativo. Utilizou-se o sofware Assistat 7.0. Para a confecção dos gráficos e determinação das equações de superfícies de resposta, foi utilizado o software TableCurve3D v.4.0.

\section{RESULTADOS E DISCUSSÃO}

As doses de micronutrientes aplicadas no solo e via foliar resultaram em efeitos lineares positivos na produção de fitomassa seca da parte aérea da planta (Figura 1), sendo que as melhores respostas foram obtidas nas maiores doses. Através da superfície de resposta, observa-se que a fitomassa seca da parte aérea apresentou comportamento linear, porém as doses de adubo foliar foram mais limitantes no acúmulo de fitomassa seca (Figura 1). Isso está associado à maior absorção de nutrientes pelas plantas nos tratamentos com maiores doses (Figura 1). Comparando-se o tratamento-controle com as maiores doses de micronutrientes, o aumento nos valores de matéria seca da parte aérea foi de 134; 290 e $234 \%$ aos 90; 180 e 270 DAP, respectivamente (Figura 1).

Esses resultados foram semelhantes aos relatados por outros autores em outras culturas. Prado et al. (2008) estudaram formas de aplicação de zinco na cultura do milho e verificaram que as aplicações de zinco via solo (incorporado e localizado) e foliar foram semelhantes no desenvolvimento inicial da cultura, porém observaram que, independentemente do modo de aplicação, o zinco promoveu incremento na altura e na produção de massa do milho.

As plantas de abacaxizeiro apresentaram respostas lineares na extração foliar de ferro quando submetidas à aplicação de micronutrientes no solo e foliar (Figura 2). Esse fato demonstra que a aplicação de micronutrientes até aos 180 DAP não induziu ao ponto de máxima absorção de Fe pelas plantas. A quantidade de Fe extraída pelas plantas de abacaxizeiro encontra-se na faixa considerada por Furlani (1999) como adequada durante esse período de desenvolvimento da cultura. Aos 180 dias após o plantio (DAP), verificou-se que, na maior dose de micronutriente aplicada via solo, a extração de Fe foi superior a testemunha em 111,33\% (Figura 2A) e quando se comparou a adubação foliar, esse aumento foi de 134\% (Figura 2B). Observa-se ainda que, no tratamento sem adubação, ocorreu aumento na extração de $\mathrm{Fe}$, nas folhas do abacaxizeiro, de $380 \%$ aproximadamente, já via foliar foi de $376 \%$.

Resultado contrário foi observado por Gupta (1991), que usando $40 \mathrm{~kg}$ de Fe ha ${ }^{-1}$ aplicado ao solo, na forma de $\mathrm{FeSO}_{4} \cdot 7 \mathrm{H}_{2} \mathrm{O}$ não observou alterações na extração de $\mathrm{Fe}$, nas folhas de aveia e cevada. Esse mesmo autor só identificou influência do Fe quando ele foi aplicado diretamente na folha, na dose de 0,2 $\mathrm{kg} \mathrm{ha}^{-1}$ de Fe como $\mathrm{FeSO}_{4} .7 \mathrm{H}_{2} \mathrm{O}$ e $0,5 \mathrm{~kg} \mathrm{ha}^{-1}$ de $\mathrm{Fe}$ como quelato.

A máxima extração de Zn pela parte aérea do abacaxizeiro foi obtida com a maior dose de FTE-12 e de adubação foliar. A extração foi crescente ao longo do tempo, com as doses utilizadas nas duas formas de adubação (Figura 3).

Em solos com alto teor de argila, grande parte dos micronutrientes aplicados pode permanecer adsorvida aos coloides, tornando-se indisponíveis às plantas. Lopes (1991) salienta que o zinco pode ser fortemente adsorvido pelos coloides do solo, o que pode dificultar a absorção pelas plantas, sendo que, conforme relatado por Rosolem e Franco (2000), tal adsorção pode ser influenciada por várias características do solo, como $\mathrm{pH}$, tipo de argila, teor de argila e teor de matéria orgânica.

Os valores médios extraídos de Mn pelo abacaxizeiro 'Vitória' estão representados na Figura 4. $\mathrm{O}$ uso de doses de FTE-12 via solo e de adubação foliar proporcionou aumentos lineares na extração foliar de Mn, que teve teores máximos de 266,7 e 269 $\mathrm{g} \mathrm{kg}^{-1}$ aos 180 DAP, nas maiores doses de adubação via solo e foliar, respectivamente (Figura 4).

As aplicações de FTE-12 e adubação foliar influenciaram significativamente na extração de boro pela parte aérea do abacaxizeiro cv. 'Vitória'. $\mathrm{O}$ comportamento linear foi o modelo que, melhor se ajustou a esse acréscimo, com coeficientes acima 
de 0,96 , mostrando que aos 180 DAP, esse comportamento se apresentou com taxas maiores comparado aos 90 DAP, nas duas formas de adubação (Figura $5)$.

Yamada (2004) cita haver uma série de trabalhos que indicam que, com a aplicação de maiores doses de boro no solo, a faixa entre a deficiência e a fitotoxidez é muito estreita. No presente estudo, não foi observado deficiência ou fitotoxidez durante o período de avaliação.

Siebeneichler et al. (2005) cultivaram mudas de abacaxizeiro cultivar 'Pérola' em solução nutritiva completa, contendo $1 \mu \mathrm{mol} \mathrm{L}{ }^{-1}$ de $\mathrm{B}$, e após 45 dias aplicaram por 3 dias consecutivos, pincelando-se as faces da folha basal com uma solução de $\mathrm{H}_{3} \mathrm{BO}_{3}$ a $10 \mathrm{mmol} \mathrm{L}^{-1}$, e aos 60 dias após aplicação, os autores constataram que o conteúdo de $\mathrm{B}$ acompanhou a variação da massa seca das plantas, sendo que o $B$ contido nessas folhas jovens $(29,8 \%$ do B total da planta) proveio das folhas mais velhas, cujo conteúdo diminuiu significativamente, confirmando a mobilidade do boro em plantas de abacaxi 'Pérola'.
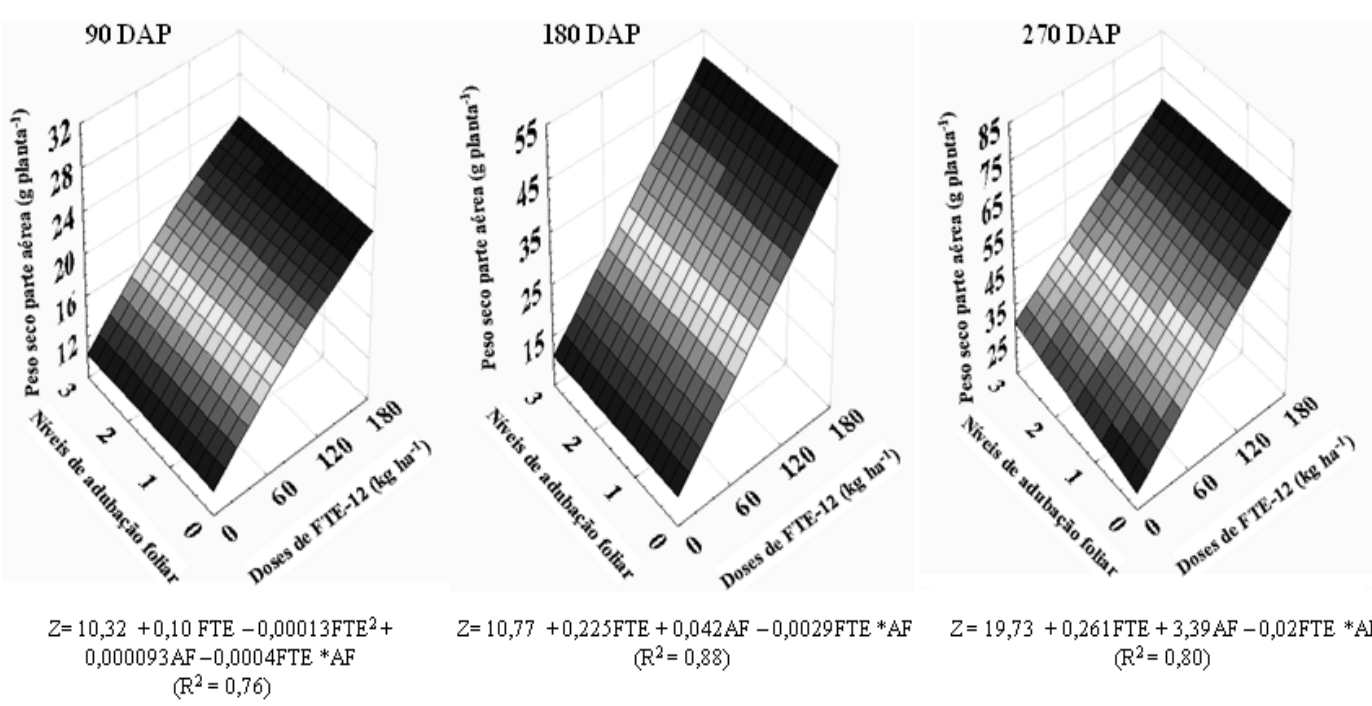

$\mathrm{Z}=10,77+0,225 \mathrm{FTE}+0,042 \mathrm{AF}-0,0029 \mathrm{FTE} * \mathrm{AF}$ $\left(R^{2}=0,88\right)$

$Z=19,73+0,261 \mathrm{FTE}+3,39 \mathrm{AF}-0,02 \mathrm{FTE} * \mathrm{AF}$ $\left(R^{2}=0,80\right)$

FIGURA 1 - Superfície de resposta do acúmulo de fitomassa seca da parte aérea de plantas de abacaxizeiro 'Vitória', em função de doses de micronutrientes aplicados via solo com FTE-12 e adubação foliar.

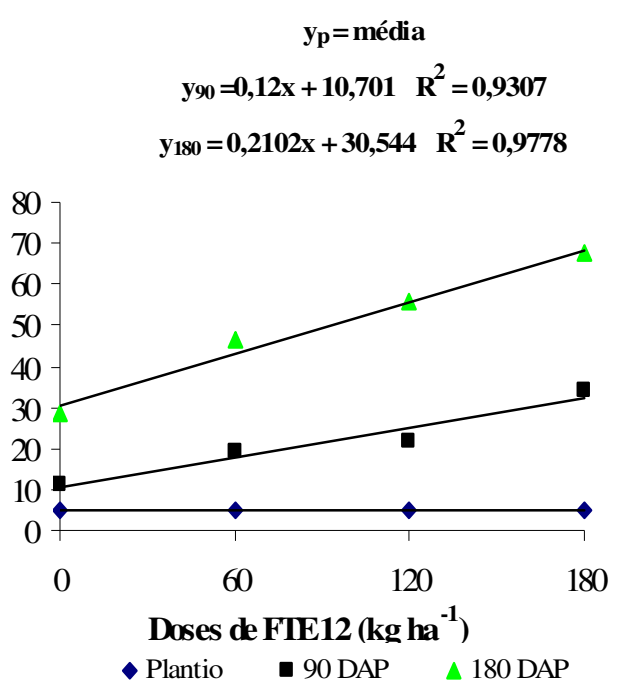

A

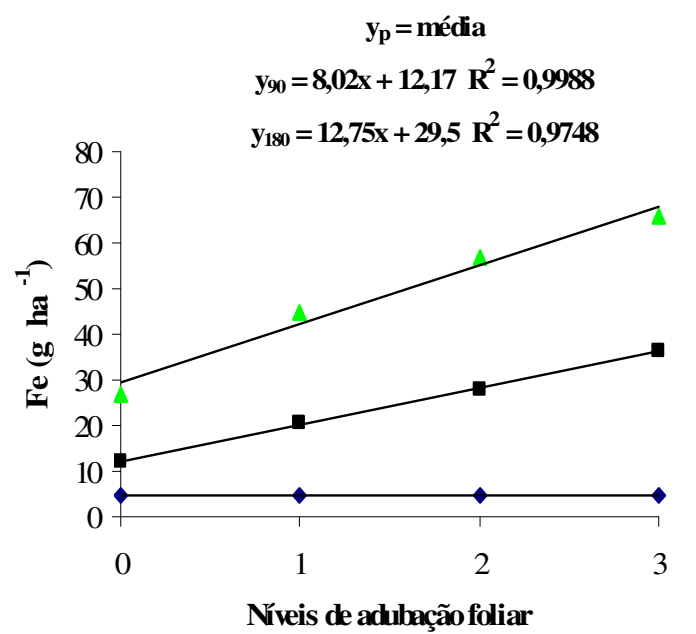

- Plantio — 90 DAP $\triangle 180 \mathrm{DAP}$

\section{B}

FIGURA 2 - Extração de Fe em folhas de abacaxizeiro 'Vitória' adubado com FTE-12 (A) e adubação foliar (B), cultivado no perímetro irrigado Baixo Acaraú - CE. 


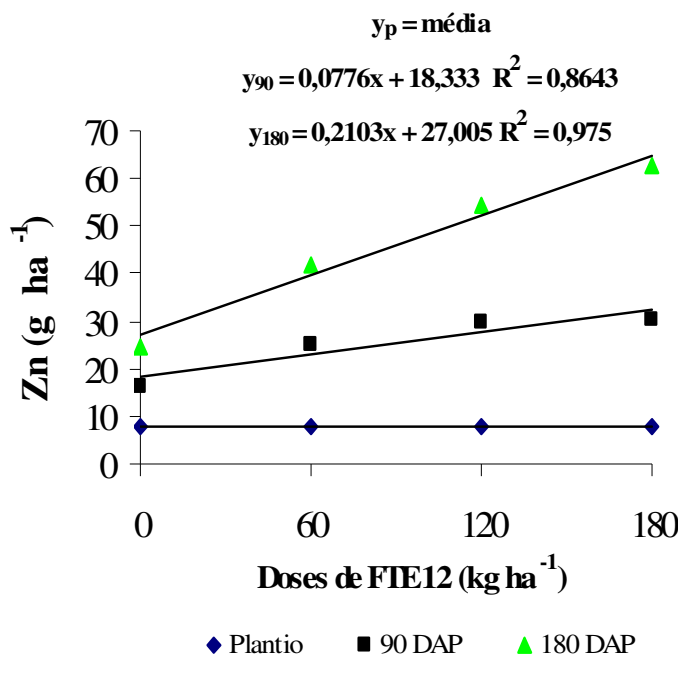

A

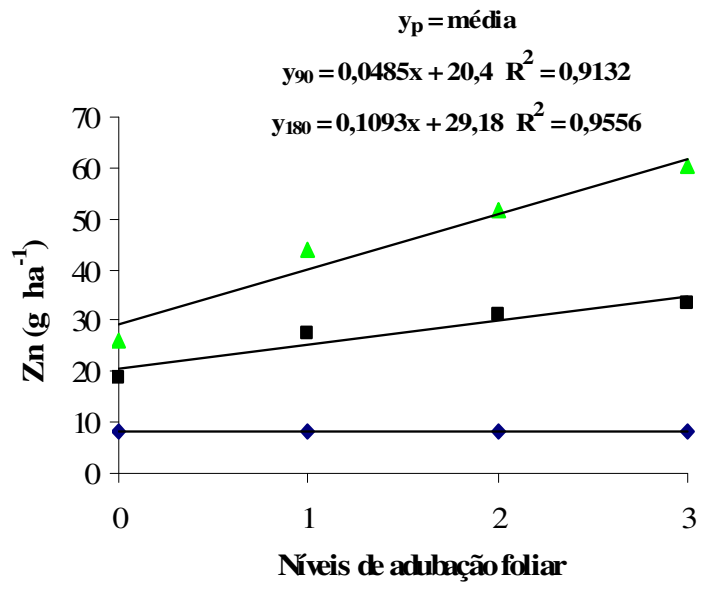

- Plantio a 90DAP $\triangle 180 \mathrm{DAP}$

B

FIGURA 3 - Extração de Zn em folhas de abacaxizeiro 'Vitória' adubado com FTE-12 (A) e adubação foliar (B), cultivado no perímetro irrigado Baixo Acaraú - CE.

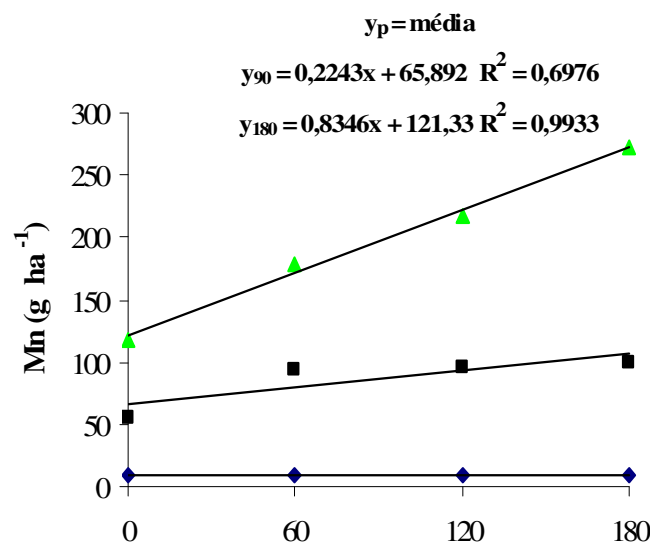

Doses de FTE12 $\left(\mathrm{kg} \mathrm{ha}^{-1}\right)$

- Plantio $\square 90 \mathrm{DAP} \triangle 180 \mathrm{DAP}$

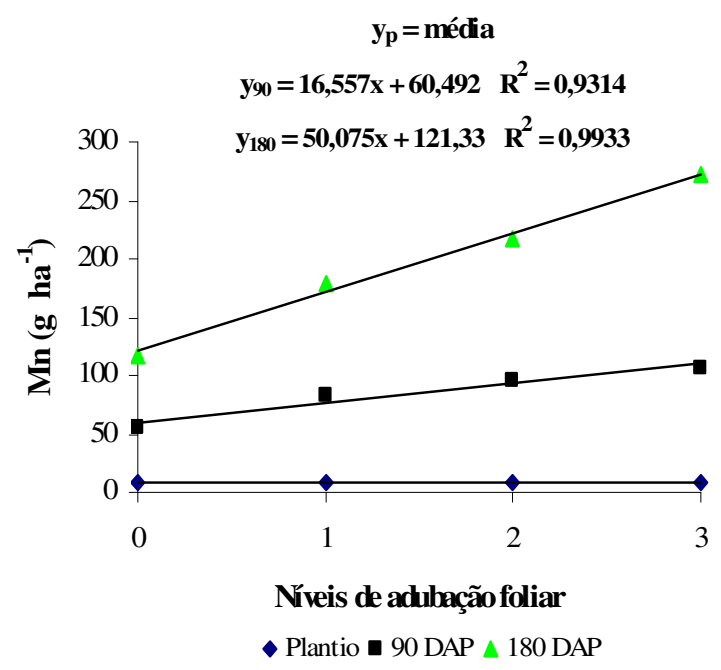

B

FIGURA 4 - Extração de Mn em folhas de abacaxizeiro 'Vitória' adubado com FTE-12 (A) e adubação foliar (B), cultivado no perímetro irrigado Baixo Acaraú - CE. 


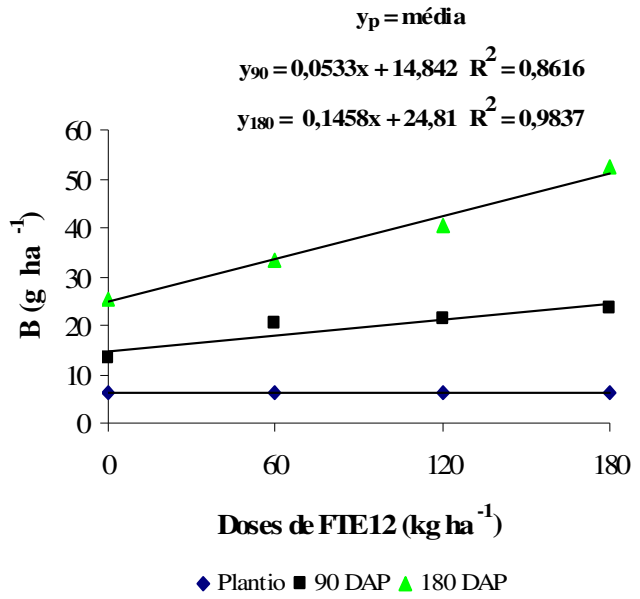

A

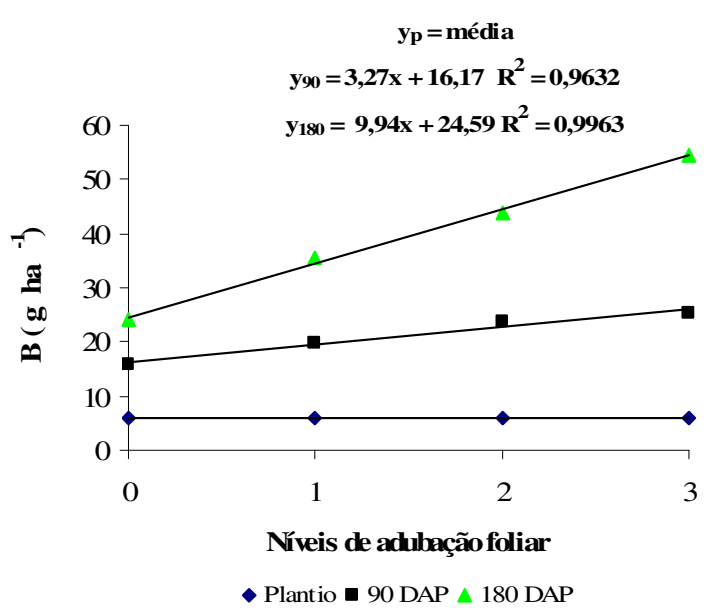

B

FIGURA 5 - Extração de B da parte aérea do abacaxizeiro 'Vitória' adubado com FTE-12 (A) e adubação foliar (B). Acaraú, CE.

\section{CONCLUSÃO}

As maiores doses de micronutrientes resultaram em maior crescimento da planta, que levou a maiores extrações de micronutrientes, porém sem atingir o ponto de máximo, indicando que a cultura pode responder a doses maiores de nutrientes do que as aplicadas no presente experimento.

\section{REFERÊNCIAS}

AGRIANUAL 2011: anuário para a agricultura brasileira. São Paulo: FNP Consultoria e Comércio, 2011.

BRITO NETO, J. F.; PEREIRA, W.S.; SOBRINHO, R.G.S.; BARBOSA, J.A.; SANTOS, D.P Aspectos produtivos da abacaxicultura familiar e Comercial no Eestado da Paraíba. Revista Caatinga, Mossoró, v.21, n.4, p.43-50, 2008.

CRUZ, T. M. L.; TEIXEIRA, A. S.; CANAFISTULA, F. G. F.; SANTOS, C. S.; OLIVEIRA, A. D.; DAHER, S. Avaliação de sensor capacitivo para o monitoramento do teor de água do solo. Engenharia Agrícola, Jaboticabal, v. 30, n. 1, p. 33-45, 2010.

FAO. FOOD AND AGRICULTURE ORGANIZATION OF THE UNITED NATIONS. Preliminary Data Now Available for Selected Countries and Products. 2009. Disponível em: <http://faostat.fao. org/site/567/DesktopDefault.aspx?PageID=567>. Acesso em: 28 set. 2010.
FURLANI, P. R.; SILVEIRA, L. C. P.; BOLONHEZI, D.; FAQUININ, V. Cultivo hidropônico de plantas. Campinas: Instituto Agronômico, 1999. 52p. (Boletim Técnico, 180).

GUPTA, U. C. Iron status of crops in Prince Edward Island and effect of soil $\mathrm{pH}$ on plant iron concentration. Canadian Journal of Soil Science, Ottawa, v. 71, p. 197-202, 1991.

LOPES, A.S. Micronutrientes: Filosofias de aplicação, fontes, eficiência agronômica e preparo de fertilizantes. In: FERREIRA, M.E.; CRUZ, M.C.P. Micronutrientes na agricultura. Piracicaba: POTAFÓS/CNPq, 1991. p. 357-390.

MAEDA, A. S.; BUZETTI, S.; BOLIANI, A.C.; BENETT, C. G. S.; TEIXEIRA FILHO, M.C.M.; ANDREOTTI, M. Foliar fertilization on pineapple quality and yield. Pesquisa Agropecuária Tropical, Goiânia, v. 41, n. 2, p. 248-253, 2011.

MALAVOLTA, E.; VITTI, G.C.; OLIVEIRA, S.A. Avaliação do estado nutricional das plantas: princípios e aplicações. 2. ed. Piracicaba: POTAFÓS, 1997. 319p.

PRADO, R. M.; ROMUALDO, L. M.; ROZANE, D. E.; VIDAL, A. A.; MARCELO, A. V. Modos de aplicação de zinco na nutrição e na produção de matéria seca do milho BRS 1001. Bioscience Journal, Uberlândia, v.24, n.1, p.67-74, 2008. 
ROSOLEM, C.A.; FRANCO, G.R. Translocação de zinco e crescimento radicular em milho. Revista Brasileira de Ciência do Solo, Viçosa,MG, v.24, p.807-814, 2000.

SIEBENEICHLER, S. C.; MONNERAT, P. H.; CARVALHO, A. J. C.; SILVA, J. A.; MARTINS, A. O. Mobilidade de boro em plantas de abacaxi. Revista Brasileira de Fruticultura, Jaboticabal, v. 27, n. 2, p. 292-297, 2005.
SIEBENEICHLER, S. C.; MONNERAT, P. H.; CARVALHO, A. J. C.; SILVA, J. A. Boro em abacaxizeiro Pérola no norte fluminense - teores, distribuição e características do fruto. Revista Brasileira de Fruticultura, Jaboticabal, v. 30, n. 3, p. 787-793, 2008.

YAMADA, T. Deficiências de micronutrientes, ocorrência, detecção e correção: o sucesso da experiência brasileira. Informações Agronômicas, Piracicaba, n. 105, p. 01-12, 2004. (Encarte técnico). 